\title{
Rapid Cyclic Fluctuations of Blood Pressure Associated with Treatment of Pheochromocytoma by Labetalol
}

\author{
Shunichi Kojıma, M.D., Takashi Natsume, M.D., \\ Keiichi Ito, M.D., and Masao IkedA, M.D.
}

\section{SUMmary}

Rapid cyclic fluctuations of blood pressure in patients with a pheochromocytoma have rarely been reported. The suitable conditions to induce this phenomenon are not adequately known. We report here a patient with an adrenal pheochromocytoma who showed this phenomenon after oral administration of labetalol.

\section{Additional Indexing Words :}

Hypertension Alpha- and beta-adrenergic blocking agents

Mayer waves

$\mathbf{I}^{\mathrm{T}}$ has been reported that labetalol, a drug with both alpha- and betaadrenoreceptor blocking activity is useful in the treatment of patients with pheochromocytoma. ${ }^{1,2)}$ We present here a patient with an adrenal pheochromocytoma who showed unusual cyclic fluctuations of blood pressure after oral administration of labetalol.

\section{Case Report}

A fifty-one year old man had been examined twice at other clinics because he had experienced attacks of dizziness, palpitation and throbbing headache. He had been informed that he had high blood pressure, but his blood pressure soon normalized without medication. Three years later, he consulted our hospital because of attacks with the same symptoms. At the outpatient department, he was suspected of having a pheochromocytoma because a qualitative test for urinary vanillylmandelic acid was strongly positive. Upon admission, his blood pressure was $240 / 110 \mathrm{mmHg}$ in the recumbent position, but it declined to $110 / 80 \mathrm{mmHg}$ in the upright position. A large mass was palpable in the right hypochondral region, and blood

From the Department of Medicine, National Cardiovascular Center Hospital, Suita, Japan. Address for reprint: Dr. Shunichi Kojima, Renal Division, Department of Medicine, National Cardiovascular Center Hospital, 5-7-1, Fujishirodai, Suita, Osaka 565, Japan.

Received for publication January 9, 1985. 

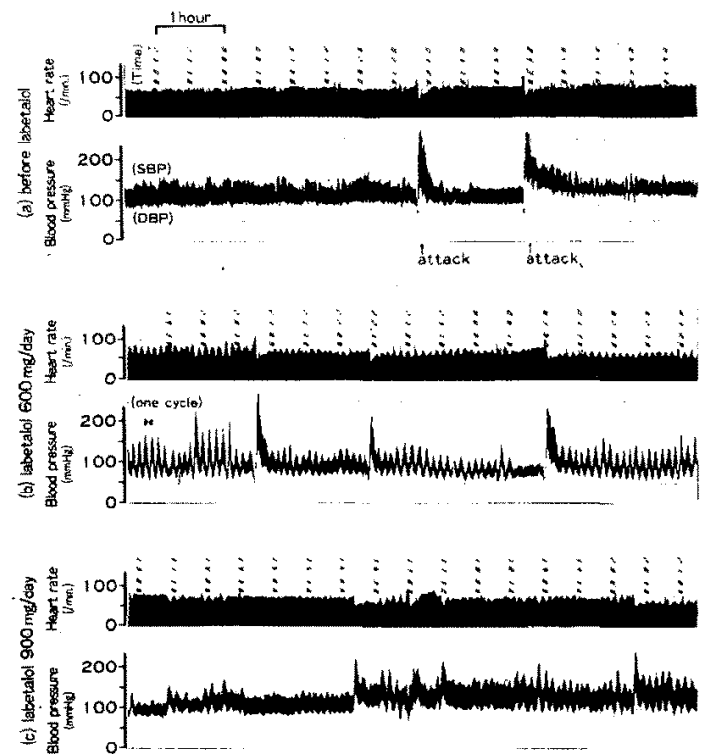

Fig. 1. Blood pressure measured directly via a catheter inserted into the brachial artery. $\mathrm{SBP}=$ systolic blood pressure; $\mathrm{DBP}=$ diastolic blood pressure.

pressure rose rapidly from $140 / 60 \mathrm{mmHg}$ to $270 / 104 \mathrm{mmHg}$ following palpation of this mass. High urinary noradrenalin excretion was confirmed (990 and $900 \mu \mathrm{g} / 24 \mathrm{~h}$ : normal up to $300 \mu \mathrm{g} / 24 \mathrm{~h}$ ), but urinary adrenalin excretion was normal $(10 \mu \mathrm{g} / 24 \mathrm{~h})$. A CT-scan demonstrated a large adrenal tumor displacing the right kidney downwards. In the center of the tumor, there was an area of hypodensity area suggesting central necrosis. Blood pressure was measured directly via a catheter inserted into the brachial artery and recorded every $30 \mathrm{sec}$ by a trend recorder (San-Ei, 6135A). Fig. la shows two incidences of blood pressure elevation recorded before treatment with labetalol. After treatment with $300 \mathrm{mg} /$ day of labetalol, the incidence of palpitations and headache increased from 3 or 4 times/day to 7 or 8 times/day. Although the dose of labetalol was increased to $600 \mathrm{~g} / \mathrm{day}$, the increased incidence of these symptoms remained unchanged. At this stage, blood pressure recorded by the same method showed rapid periodic fluctuations with cycles of 5 or 6 min (Fig. 1b). Heart rate measured from the R-R interval of the EGG reflected an inverse relationship to blood pressure. After the dose of labetalol was increased to $900 \mathrm{mg} /$ day, the fluctuation of blood pressure disappeared (Fig. 1c) and the frequency of symptoms was reduced to 1-3 times/ day. After about 1 month of therapy with phenoxybenzamine, during which 
time no attacks were observed, a right adrenal pheochromocytoma was removed. The weight of the tumor was $820 \mathrm{~g}$. Blood pressure and urinary noradrenalin excretion returned to normal.

\section{Discussion}

Rapid cyclic fluctuations of blood pressure in patients with pheochromocytoma have rarely been documented. ${ }^{31,4)}$ In one report, a catecholaminesecreting glomus juglare tumor was associated with such a phenomenon, ${ }^{3}$ ) In another report, hypovolemia caused a similar phenomenon in a patient with an adrenal pheochromocytoma.4) Our case had a large adrenal pheochromocytoma, but there were no signs that suggested hypovolemia. Since rapid cyclic fluctuations of blood pressure were observed after administration of labetalol, the phenomenon seemed to be provoked by labetalol. Labetalol is much more potent as a beta- than an alpha-adrenoreceptor blocking agent.5) Thus, low doses of labetalol might have increased the frequency of attacks through its beta-adrenoreceptor blocking action since rapid cyclic fluctuations of blood pressure were observed only with smaller doses of labetalol in our case.

\section{REFERENGES}

1. Rosei EA, Brown JJ, Lever AF, Robertson AS: Treatment of phaeochromocytoma and clonidine withdrawal hypertension with labetalol. Br J Clin Pharmac 3 (4 Suppl 3): 809, 1976

2. Reach G, Thibonnier M, Chevillord $\mathrm{C}$, Corvol P, Milliez P: Effect of labetalol on blood pressure and plasma catecholamine concentrations in patients with pheochromocytoma. $\mathrm{Br}$ Med J 280: 1300, 1980

3. Matsuguchi H, Tsuneyoshi M, Takeshita A, Nakamura M, Kato T, Arakawa K: Noradrenalin secreting glomus jugulare tumor with cyclic change of blood pressure. Arch Intern Med 135: 1110, 1975

4. Ganguly A, Grim CE, Weinberger MH, Henry DP: Rapid cyclic fluctuations of blood pressure associated with an adrenal pheochromocytoma. Hypertension 6: 281, 1984

5. Brittain RT, Levey GP: A review of the animal pharmacology of labetalol, a combined alpha- and beta-adrenoreceptor-blocking drug. Br J Pharmac 3 (4 Suppl 3):681, 1976 